\title{
PrP Gene Polymorphism in Medieval Remains of Sicilian Sheep
}

\author{
Stefano Reale1, Mario Cosenza1, Luca Sìneo ${ }^{2}$, Letizia Arcoleo ${ }^{2}$, Gabriele Zaffora1, \\ Daniele Macrì1, Fabrizio Vitale ${ }^{1}$ \\ ${ }^{1}$ Molecular Biology Department, Istituto Zooprofilattico Sperimentale della Sicilia "A. Mirri", Palermo, Italy \\ ${ }^{2}$ Laboratory of Anthropology, STEBICEF Department, University of Palermo, Palermo, Italy \\ Email: stefano.reale@izssicilia.it, mario.cosenz@gmail.com, luca.sineo@unipa.it, letizia.arcoleo@unipa.it, \\ g.zaffora@katamail.com, daniele.macri@izssicilia.it, fabrizio.vitale@izssicilia.it
}

Received 9 September 2015; accepted 23 October 2015; published 26 October 2015

Copyright (C) 2015 by authors and Scientific Research Publishing Inc.

This work is licensed under the Creative Commons Attribution International License (CC BY). http://creativecommons.org/licenses/by/4.0/

(c) (i) Open Access

\section{Abstract}

Encephalopathy in sheep was at first described in Ireland in 1732 and was called scrapie. Ancient DNA in archaeogenetics represents an effective method to evaluate the ancestral pedigree of living animals and track evolutionary changes occurred between the past and the present day. Since several point mutations are today widely described in modern scrapie, no data about both sequence and frequency are still available for the prion protein (PrP) gene in ancient breeds. In order to evaluate whether the haplotypes distribution in ancient sheep differed from those of the modern population we evaluated polymorphism at four well know codons of the Prp Open Reading Frame. In the present work, we collected 37 medieval sheep bone remains found at the Calathamet $(n=11)$, Palazzo Bonagia $(n=12)$ and Palazzo Steri $(n=14)$ Sicilians archeological sites and dated back between $9^{\text {th }}-15^{\text {th }}$ century. Single nucleotide polymorphisms (SNPs) at codons 136, 141, 154 and 171 of the prion protein (PrP) were investigated using cycle sequencing. Sequenom Mass ARRAYiPLEX platform confirmed the results for 5 individuals out of 37 . Cycle sequencing showed at all samples the $A_{136} L_{141} R R_{154} Q_{171}$ (hereafter $\left.A L R Q / A L R Q\right)$ genotype except at 2 individuals showing the very susceptible genotype VLRQ/VLRQ $(n=1)$ and the resistant (ALRR/ ALRR) ( $n=1)$ respectively. Supported by a high incidence of susceptible genotype to prion infection we concluded that presumably scrapie was already widespread enough in the medieval Sicily. Moreover, we described conceivable scenarios that could have underlain evolutionary changes in the medieval sheep population.

\section{Keywords}

Scrapie, Prion Protein, SNPs, Ancient Genotype 


\section{Introduction}

Scrapie or prion disease belongs to the transmissible spongiform encephalopathies (TSEs) together with bovine spongiform encephalopathy (BSE) in cattle and chronic wasting disease (CWD) in deer. Scrapie is a fatal neurodegenerative disorder that affects genetically susceptible sheep and goat and it is characterized by the deposition of the aberrant isoform of the natural prion glycoprotein. It is revealed that the PrP abnormal prion protein form, consist of an approximately $40 \%$ of beta sheet folding that makes it protease resistant and infectious [1]. Scrapie disease is also the oldest form of TSEs and various data indicate that it was already present in Europe in eighteenth century or earlier. The first description of scrapie case came back to the year 1750 by Leopoldt [2] who reported the infectious nature. Since that time several studies were conducted to describe the early history of the TSEs [3] and only two centuries later it was reported the first signal of scrapie in Italy, in the Biellese breed (Piedmonte), described by Cravero et al., 1976 [4]. PrP polymorphisms are highly debated and to date their involvement in scrapie is not completely clear. Specific point mutations in the coding region are widely linked to susceptibility in sheep to develop prion disease [5]. Several SNPs are currently reported [6] and four wellknown codons show crucial importance in modulate genetic susceptibility to classical scrapie. Amino acid polymorphism at codon 136 (Alanine/Valine; A/V), codon 141 (Leucine/Phenylalanine; L/F), codon 154 (Arginine/ Histidine; R/H) and codon 171 (Arginine/Glutamine/Histidine; R/Q/H) are extensively described in literature [7]-[9]. The ARR/ARR is associated with a high resistant genotype to natural scrapie [7] [9] [10], while AHQ haplotype is associated only in some breeds with the resistance to disease [11]. In contrast, the VRQ confers high susceptibility both homozygosis and heterozygosis [12] [13]. The ARQ represents the most common haplotype [14] and exhibits high to moderate susceptibility to disease while the ARH allele seems to be neutral [15]. Based on the above evidence, several PrP genotypes subsist within the population and each of them is related with a different degree of proneness to develop scrapie (R1 - R5, respectively from very low risk to high susceptibility). When DNA are well preserved, direct sequencing represents definitely the most reliable and powerful tools to decode ancient genes and to track genetic variability along the time-scale. In line with this premises, we thought the PrP gene as a target of possible evolutionary pressure reflecting the characteristics of living animals.

To date, Italian data on the amino acid frequencies at PrP gene are available and show the prevalence of the ARQ both homozygosis and heterozygosis with the ARR [16]. In the Sicilian sheep the haplotypes distributions follow the same trend as the rest of the Italian population [17] despite the genetic isolation that characterizes the native sheep breeds. Since there are no data available on the ancestral genotype distribution for the Sicilian sheep, through a retrospective study we evaluated PrP allelic profile using aDNA analysis directly from archaeological samples. To this aim we searched for amino acid variations in order to assess whether the ancestral sheep already had at that time a certain level of susceptibility to prion infection. We estimated the ancestral genotype and compared them with those of the contemporary sheep by employing direct sequencing and mass spectrometry MALDI-TOF.

\section{Materials and Methods}

A specimen of 37 ovine bones (Ovis aries) from medieval periods was examined. Samples came from three different ancient sites of the town of Palermo in Italy: Palazzo Bonagia (12 specimens), Palazzo Steri (14 specimens) and Calathamet (11 specimens) [18] [19] in the north-west of Sicily. Scans and analysis of the artifacts discovered in the proximity of the specimens revealed that the relics of Palazzo Bonagia can be dated back to a period between the end of the $9^{\text {th }}$ century and the beginning of the $11^{\text {th }}$ century A.D.; the specimens of Calathamet can be dated back to $11^{\text {th }}-14^{\text {th }}$ century A.D. [18] whereas the specimens of Palazzo Steri can be dated back to $11^{\text {th }}-15^{\text {th }}$ century A.D. For the site of Calathamet only the samples attributed to $13^{\text {th }}$ century A.D. were analyzed and, analogously for Palazzo Steri, only the relics of the "Chiaramonte" period $\left(14^{\text {th }}-15^{\text {th }}\right.$ century A.D.) were considered. Since some skeletal remains were badly preserved and damaged, various bone elements were sampled in order to form the highest Minimum Number of Individuals (MNI). Samples were selected by choosing the same anatomical part and the same side, in order to be sure not to collect and analyze twice the same individual. Young-to-adults individuals with an age of death included in a range of 18 to 36 months represented the specimen. We managed directly aDNA from the sheep skeletal remains according to the strict practices provided by Cooper and Poinar, 2000 [20]. To assure sterility, all the work surfaces were treated with $1 \%$ sodium hypochlorite solution and equipment and pipettors exposed to UV rays. Latex gloves, mask and body suit were used by researchers during handling of the bones. A fragment for each animal was collected under sterile condi- 
tions in a pre-PCR area exclusively dedicated and soaked in 10\% bleach. A 80 - 100 mg were powdered mechanically in a homogenizer. Ancient DNA was extracted according to Yang's et al. protocol, 1998 [21] in a dedicate extractions area within the laboratory and in a laminar flow hood (HEPA-filtered) in order to avoid cross-contamination with modern DNA. Bone powder was decalcified with EDTA $0.5 \mathrm{M}$ pH 8 at room temperature for $48 \mathrm{~h}$ and then incubated in a thermo mixer at $55^{\circ} \mathrm{C}$ overnight with $20 \mathrm{mg} / \mathrm{ml}$ proteinase $\mathrm{K}$ and $0.5 \%$ SDS. The solution was centrifuged at $2000 \times \mathrm{g}$ for 5 minutes and the supernatant was transferred into a sterile microtube to perform DNA purification with the QIAquick PCR Purification Kit (Qiagen, Sweden) following the manufacturer's instructions. New reagents for aDNA extraction, PCR amplification and multiple downstream applications were used. Non-template control and reagent blanks were employed to check exogenous contamination throughout working procedure. Direct sequencing was initially performed on a 225 bp fragment using a couple of primer provided by Acutis et al. (2010) [22] including all codons investigated in one amplicon. At this condition PCR amplification did not showed any amplicon because of the too high dimension of the fragment to be amplified related to the degree of degradation of the aDNA. In light of this we amplified each codon independently, except at codons 136 and 141 because of their closeness. For this purpose, new mini primer for the selective amplification of the codons 136/141, 154 and 171 were suitably in-house designed, as illustrates Table 1. The oligos hybridize on the PrP open reading frame at positions 386 - 407 and 506 - 485 for the codon 136 - 141 (respectively forward and reverse); 429 - 447 and 558 - 539 for the codon 154; 504 - 523 and 619 - 599 for the codon 171 [GenBank:AJ000739]. The couple of primers for each codon annealed at strategic positions so that SNPs were identified close to the reverse primer. The amplification was performed in a final reaction volume of $50 \mu \mathrm{l}$ using AmpliTaq Gold 360 DNA Polymerase (Applied Biosystems, Foster City, California, USA). The amplification was performed in a GeneAmp PCR system 9700 (Applied Biosystems, Foster City, California) with an initial hold of $8 \mathrm{~min}$ at $95^{\circ} \mathrm{C}$ followed by 40 cycle of $45 \mathrm{sec}$ at $95^{\circ} \mathrm{C}, 50$ sec at $56^{\circ} \mathrm{C}$ and $30 \mathrm{sec}$ at $72^{\circ} \mathrm{C}$; a final extension period of $10 \mathrm{~min}$ at $72^{\circ} \mathrm{C}$ was employed. Products were ran on the automated capillary electrophoresis device QIAxcel (Qiagen, Milano, Italy) to avoid handling of samples, cleaned up and started toward the cycle sequencing using BigDye Terminator v3.1chemistry(Applied Biosystems, Foster City, California, USA). The amplicon was newly cleaned up with BigDye X-Terminator purification kit and running on a ABI Prism 3130 Genetic Analyzer (Applied Biosystems, Foster City, California, USA). Each sequence was submitted to the BLAST alignment tool to be sure not to have contamination and aligned using SeqScape Software v2.7 (Applied Biosystems, Foster City, California, USA) to check PrP polymorphisms. Each sample was also amplified using a specific iPLEX Genotyping kit named MyriapodScrapie (DiatechPharmacogenetics, Jesi, Italy) exclusively designed for the detection at the same time of the polymorphism at codons 136, 141, 154 and 171. A first PCR amplification was performed using AMP-Mix prepared according to the manufacturer's instructions. Briefly three microliters were dispensed in each tube and $2 \mu \mathrm{l}$ of DNA (1 - $100 \mathrm{ng} / \mu \mathrm{l})$ were used. The plate was sealed using a SQ foil and amplified on a Labcycler (SensoQuest, GmbH) using the following protocol: initial hold of $95^{\circ} \mathrm{C}$ for 2 min followed by 45 cycle of $30 \mathrm{sec}$ at $95^{\circ} \mathrm{C}, 30 \mathrm{sec}$ at $56^{\circ} \mathrm{C}$ and 1 min at $72^{\circ} \mathrm{C}$. Two additional sequential hold of $72^{\circ} \mathrm{C}$ and $4^{\circ} \mathrm{C}$ each for 5 min were also performed. After the first amplification, a SAP treatment is required to cleans up left over primers and dNTPs using $2 \mu$ l of a specific SAP-Mix in 5 $\mu \mathrm{l}$ of PCR product; the following thermal profile was applied: $37^{\circ} \mathrm{C}$ for $40 \mathrm{~min}, 85^{\circ} \mathrm{C}$ for 5 min and $4^{\circ} \mathrm{C}$ for 5 min. Afterwards a primer single-base extension was performed preparing a specific EXT-Mix following the manufacturer's instructions. Two microliter of the mix were added to previous tube reaching a final volume of 9 $\mu 1$. A specific iPLEX PCR protocol was applied: $94^{\circ} \mathrm{C}$ for $30 \mathrm{sec}$ followed by 40 cycle of $94^{\circ} \mathrm{C}$ for $5 \mathrm{sec}$ and annealing and extension repeated 5 times for each cycle, respectively of $52^{\circ} \mathrm{C}$ and $80^{\circ} \mathrm{C}$ for $5 \mathrm{sec}$. A further hold of $72^{\circ} \mathrm{C}$ for $3 \mathrm{~min}$ and $4^{\circ} \mathrm{C}$ for $5 \mathrm{~min}$ was also applied. Extension products were nanodispensed to a SpectroCHIParray and transferred to the MassARRAY for the analysis of the fragments of allele-specific mass. The mass

Table 1. Mini primer for the selective amplification of the codons 136/141, 154 and 171; Ta, annealing temperature.

\begin{tabular}{cccc}
\hline Primer Name & Primer 5' $-3^{\prime}$ & Size (bp) & Ta $\left({ }^{\circ} \mathrm{C}\right)$ \\
\hline MC136/141-F & CAGTAAGCCAAAAACCAACATG & 121 \\
MC136/141-R & GCCAAAATGTATAAGAGGCCTG & & \\
MC154-F & GCAGCTGGAGCAGTGGTAG & 130 & 56 \\
MC154-R & GGTTGGGGTAACGGTACATG & \multirow{2}{*}{116} \\
MC171-F & GGCAATGACTATGAGGACCG & \\
MC171-R & ACACAGTCATGCACAAAGTTG \\
\hline
\end{tabular}


difference allows the software to discriminate between different SNP alleles at each codon using the Sequenom MassARRAY Analyzer 4 (Diatech Pharmacogenetics, Jesi, Italy). For the same reasons mentioned above, the allele-mass peak was not always detected because of the amplicon length ( $400 \mathrm{bp})$.

\section{Results}

Despite some badly preservation and dating of the bones, ancient DNA resulted in a positive amplification for all codons investigated (Figure 1). Sheep skeletal remains were analyzed in double, confirming the results without any incongruence and therefore considering it as authentic. Sequencing analysis showed for all sample a 94.6\% of ALRQ/ALRQ genotype; the remaining was VLRQ/VLRQ and ALRR/ALRR (2.7\% each). We have not found nucleotide mutation leading to amino acid change or synonymous substitution so that we excluded artifacts in a DNA amplification induced by e.g. deamination of cytosine [23]. We have detected triplets GCC (Ala/Ala) and GTC (Val/Val) at codon 136, CTT at codon 141 (Leu/Leu), CGT at codon 154 (Arg/Arg), CGG (Arg/Arg) and CAG (Gln/Gln) at codon 171. Sequencing positive control was heterozygote at codon 171 (ARR/ARQ). Mass spectrum results confirmed cycle sequencing data for four ARQ homozygotes and one susceptible VRQ both belonging to the Calathamet site, showing a better DNA preservation of these samples (Figure 2(a) and Figure 2(b)). The remaining samples did not revealed any signal on mass array.
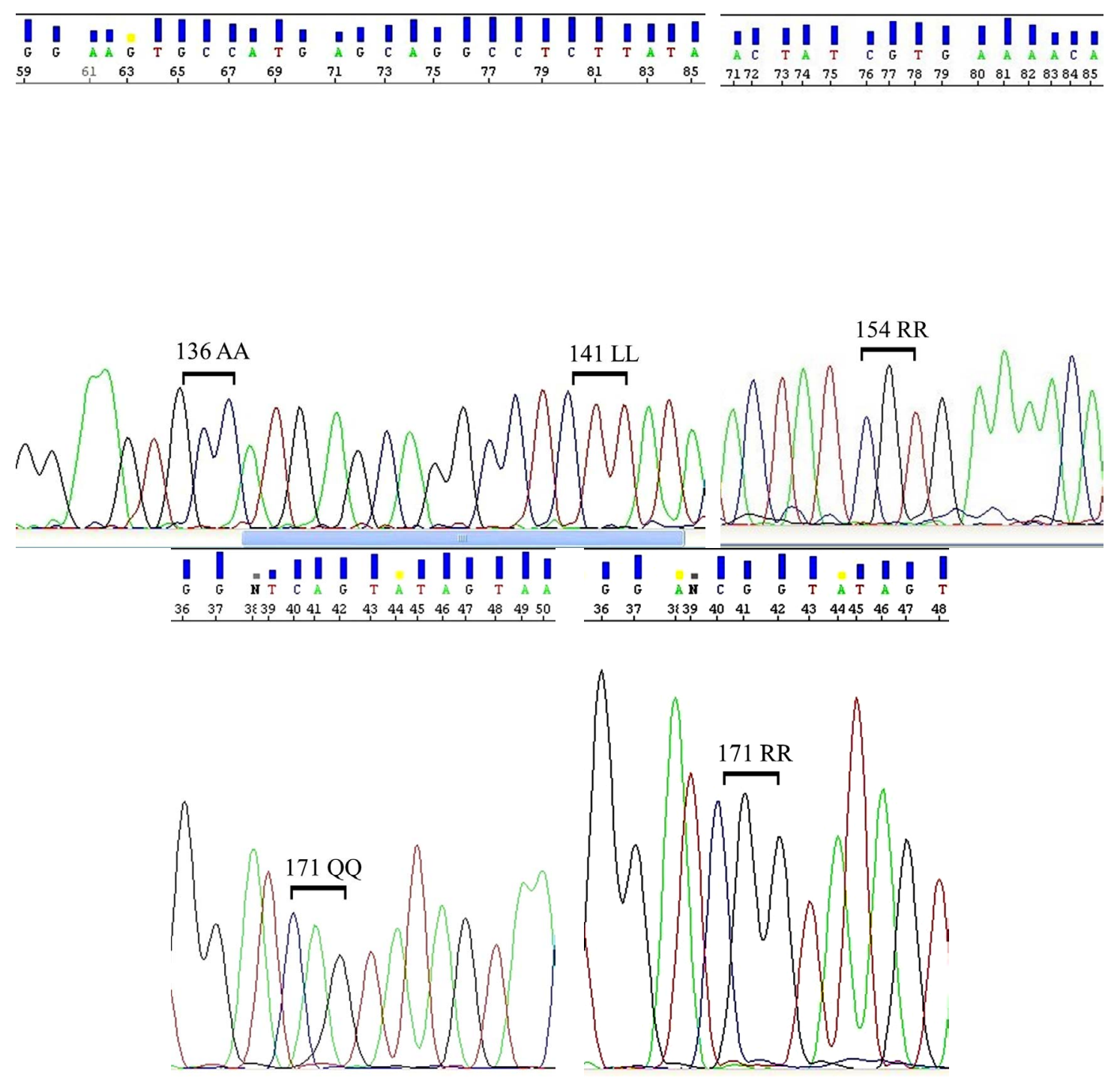

Figure 1. Cycle sequencing of the codons 136 - 141, 154 and 171. 

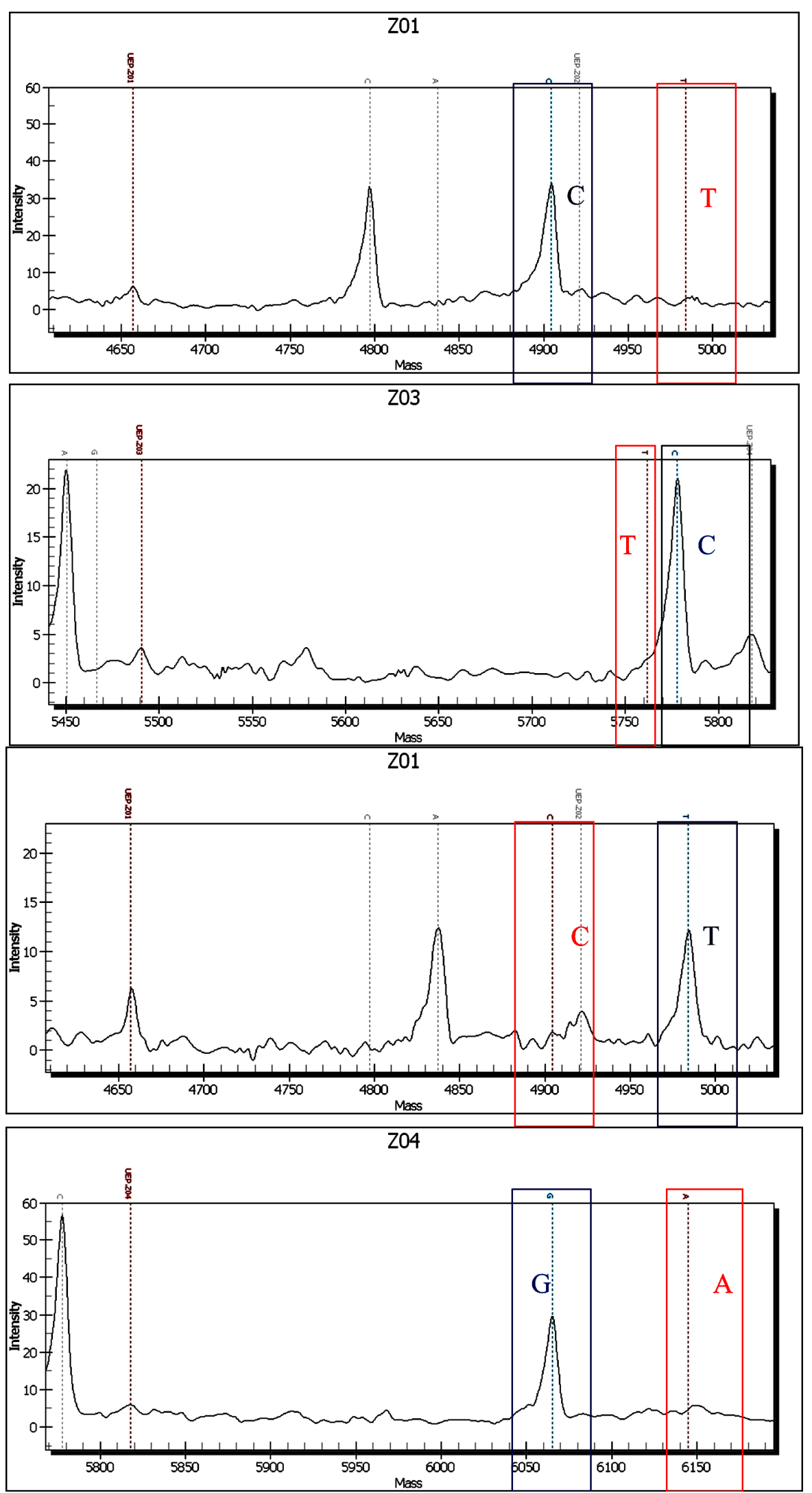

(a) 


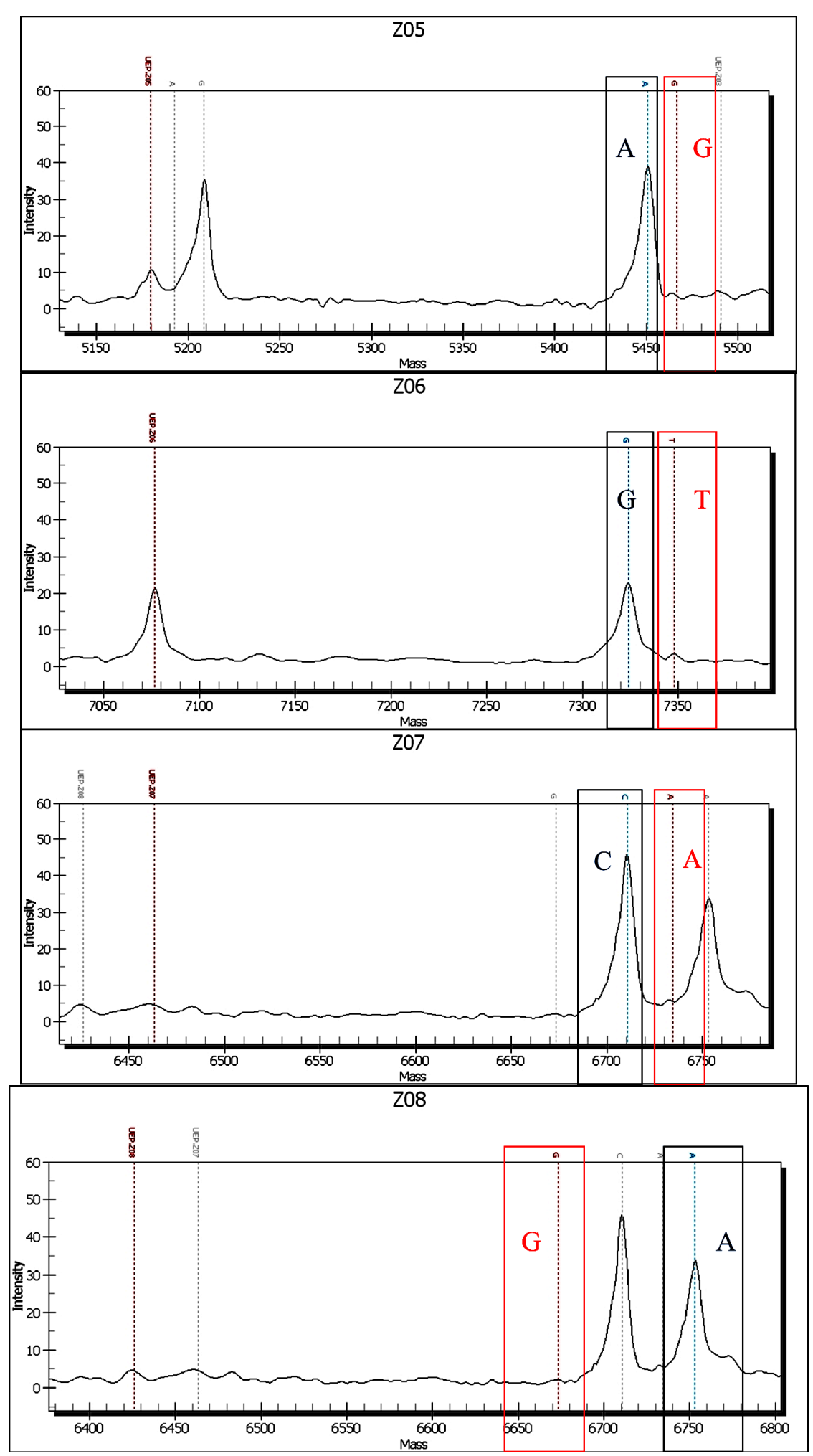

(b)

Figure 2. (a) Mass spectrum chromatogram. Panels Z1 to Z4 represent a definite nucleotide assay at one specific codon. Z1 A136V (G드 - GTC); Z3 L141F (CTT - TTT); Z4 R154H (CGT - CÁT). (b) Mass Array spectrum for the codon 171. Pa-

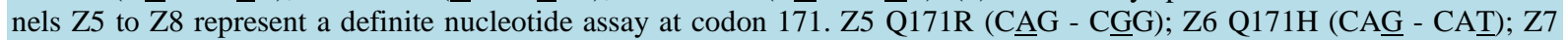
Q171K (ㅡAG - $\underline{A} A G) ; Z 8$ work as control of Z5 analysis $(A \rightarrow G)$ using a different primer. 


\section{Discussion and Conclusions}

Scrapie disease is a lethal disorder affecting genetically susceptible sheep. The aim of this study was to assess the allelic pattern at codons 136, 141, 154 and 171 in order to estimate whether scrapie was already infectious in medieval era. Moreover, we presumed genetic forces driving evolutionary changes occurred in the ancestral sheep population. The predominant ALRQ haplotypes found in this study are in line with the modern allelic distribution in Sicily [17]. According to the Van Kaam study, currently the ARQ haplotype mean frequency in Sicilians sheep is much higher (56.2\%) compared to the resistant ARR (34.8\%). Despite this, the heterozygotes ARR/ARQ are today the most representative genotypes of the Sicilian ovine population (mean 39.9\%) and only secondly the homozygotes ARQ/ARQ (mean 31.4\%). The ARR/ARR genotype is poorly represented within the population (mean 12.1\%) tending to its increase using selective mating strategies under EU member states plan. In our study, the ancestral ALRQ/ALRQ appears to be the predominant genotype for the Sicilian sheep. Only one sample showed the Valine (V) allele at codon 136 whereas another sample displayed the Arginine (R) allele at codon 171. No heterozygotes were detected showing slightly differences among ancient and contemporary sheep breeds. In light of this, we wondered why the prion protein gene already had in the middle age a scrapiesusceptible form. Lacking or poorness of scrapie resistant genotype in European sheep [24]-[26] could be due to anthropic and selective pressures that have acted in past affecting genetics of the present days. It's clear today that domestication took place about in 4000 B.C. by Neolithic settlers as shown by findings of skeletal remains. During that time, the most common use of medieval sheep was to provide milk, wool and meat and as results of anthropic pressure probably they were selected for their somatic characteristics (e.g. long or short wools, white-faced, polled or horned). Unfortunately, to our knowledge no study was conducted nor results are reported linking phenotype with polymorphisms of susceptibility. On the other hand, evolutionary changes may have took place over the last centuries in the Sicilian Island involving sheep population. As shown in this work, a small proportion of resistant alleles were already present and only secondly lost or strongly reduced perhaps due to accidental crossing with breeds carrying the susceptible alleles. Alternatively, it might be also possible that migrations of incoming sheep population could have interacted genetically with the autochthonous with a significative changing in the haplotype frequencies. Unfortunately these happenings may be difficult to investigate. Moreover Sicilians sheep might have been progressively selected for different alleles due to stochastic effects such as genetic drift and bottlenecks. In line with this assumptions, founder effect could have supported the selection process by forming a new population starting from a few number of sheep survived and carrying e.g. the $\mathrm{Q}_{171}$ allele. These occurrences most likely have led to the differentiation of the sheep breeds as we know them today and to the fragmentation of their genetic variability. It would be reasonable to consider a driving force favoring the protective form (e.g. $\mathrm{RR}_{171}$ ) rather than those susceptible. This might suggest more simply that selective pressure acting on the PrP alleles could be also the answer to an evolutionary adaptation to date unknown. From a contemporary point of view, artificial selection could be responsible for the large $\mathrm{Q}_{171}$ increase within the modern Sicilian sheep population due to a wrong in-house breeding program. This issue is strengthened by the disproportion between male and female that form today the Italians sheep flock. In such breeding program, Sicilian sires carrying glutamine allele at codon 171 are unknowingly used as reproducers, spreading the susceptible haplotype. This led to consolidate and disseminate the current frequencies. For reasons to date unclear, the genotype obtained from the medieval sheep bones differs if compared to the modern sheep. In our study, the ancient haplotypes seem to be lacking at codon 171 of the resistant triplet leading to the amino acid Arginine or could be simply infrequent variants within the ancient sheep and therefore hard to detect [27]. On the other hand, the high ALRQ proportion could be overestimated precluding the possibility to find coding mutations. Despite the limited number of bones analyzed, we assumed however that sampling derived from the different ancient sites was considered representative of the historical period. We concluded that scrapie mutation was observed in any of the samples analyzed. On the basis of objective observations, we could confirm that in the period $9^{\text {th }}$ $15^{\text {th }}$ century scrapie was widespread as demonstrated by the high incidence of susceptible genotype found. Our data represent only a piece of a larger scenario that need of insights but that may contribute to shed some light on the geneflow phenomena occurred between present and past as well in tracking selection events.

\section{References}

[1] Prusiner, S.B. (1991) Molecular Biology of Prion Diseases. Science, 252, 1515-1522. http://dx.doi.org/10.1126/science.1675487 
[2] Leopoldt, J.G. (1750) Nutzliche und auf die Erfahrung gegrundete Einleitung zu der Land-Wirthschafft, 5, Johann Gottlieb Rothen, Sorau.

[3] Schneider, K., Fangerau, H., Michaelsen, B. and Raab, W.H.M. (2008) The Early History of the Transmissible Spongiform Encephalopathies Exemplified by Scrapie. Brain ResearchBulletin, 77, 343-355. http://dx.doi.org/10.1016/j.brainresbull.2008.09.012

[4] Cravero, G., Guarda, F., Dotta, U. and Guglielmino, R. (1976) La scrapie in pecore di razza biellese. Prima segnalazione in Italia. La Clinica Veterinaria, 100, 1-14.

[5] Bossers, A., Belt, P.B.G.M., Raymond, G.J., Caughey, B., de Vries, R. and Smits, M.A. (1997) Scrapie SusceptibilityLinked Polymorphismsmodulate the in Vitro Conversion of Sheep Prion Protein to Protease Resistantforms. Proceedings of the National Academy of Sciences, USA, 94, 4931-4936. http://dx.doi.org/10.1073/pnas.94.10.4931

[6] Heaton, M.P., Leymaster, K.A., Freking, B.A, Hawk, D.A., Smith, T.P., Keele, J.W., Senlling, W.M., Fox, J.M., Chitko-McKown, C.G. and Laegreid, W.W. (2003) Prion Gene Sequence Variation within Diverse Groups of U.S. Sheep, Beef Cattle, and Deer. Mammalian Genome, 14, 765-777. http://dx.doi.org/10.1007/s00335-003-2283-y

[7] Goldmann, W., Hunter, N., Smith, G., Foster, J. and Hope, J. (1994) PrP Genotype and Agent Effects in Scrapie: change in Allelic Interaction with Different Isolates of Agent in Sheep, a Natural Host of Scrapie. Journal of General Virology, 75, 989-995. http://dx.doi.org/10.1099/0022-1317-75-5-989

[8] Clouscard, C., Beaudry, P., Elsen, J.M., Milan, D., Dussaucy M., Bounneau C., Schelcher, F., Chatelain, J., Launay, J. M. and Laplanche, J.L. (1995) Different Allelic Effects of the Codons 136 and 171 of the Prion Protein Gene in Sheep with Natural Scrapie. Journal of General Virology, 76, 2097-2101. http://dx.doi.org/10.1099/0022-1317-76-8-2097

[9] Hunter, N., Goldmann, W., Smith, G. and Hope, J. (1994) The Association of a Codon 136 PrP Gene Variant with the Occurrence of Natural Scrapie. Archives of Virology, 137, 171-177. http://dx.doi.org/10.1007/BF01311184

[10] Baylis, M., Goldmann, W., Houston, F., Cairns, D., Chong, A., Ross, A., Smith, A., Hunter, N. and McLean, A.R. (2002) Scrapie Epidemic in a Fully PrP-Genotyped Sheep Flock. Journal of General Virology, 83, 2907-2914. http://dx.doi.org/10.1099/0022-1317-83-11-2907

[11] Thorgeirsdottir, S., Sigurdarson, S., Thorisson, H.M., Georgsson, G. and Palsdottir, A. (1999) PrP Gene Polymorphism and Natural Scrapie in Icelandic Sheep. Journal of General Virology, 80, 2527-2534. http://dx.doi.org/10.1099/0022-1317-80-9-2527

[12] Belt, P.B., Muileman, I.H., Schreuder, B.E., Bos-de Ruijter, J., Gielkens, A.L. and Smits, M.A. (1995) Identification of Five Allelic Variants of the Sheep PrP Gene and Their Association with Natural Scrapie. Journal of General Virology, 76, 509-517. http://dx.doi.org/10.1099/0022-1317-76-3-509

[13] Hunter, N., Foster, J.D., Goldmann, W., Stear, M.J., Hope, J. and Bostock, C. (1996) Natural Scrapie in a Closed Flock of Cheviot Sheep Occurs Only in Specific PrP Genotypes. Archives of Virology, 141, 809-824. http://dx.doi.org/10.1007/BF01718157

[14] Baylis, M. and Goldmann, W. (2004) The Genetics of Scrapie in Sheep and Goats. Current Molecular Medicine, 4, 385-396. http://dx.doi.org/10.2174/1566524043360672

[15] Dawson, M., Hoinville, L.J., Hosie, B.D. and Hunter, N. (1998) Guidance on the Use of PrP Genotyping as an Aid to the Control of Clinical Scrapie. Veterinary Record, 142, 623-625.

[16] Pongolini, S., Bergamini, F., Iori A., Migliore, S., Corradi, A. and Bassi, S. (2009) Prion Protein Genotypes of Italian Sheep Breeds with Lysine-171 and Phenylalanine-141 Detection. Veterinary Microbiology, 137, 18-23. http://dx.doi.org/10.1016/j.vetmic.2008.12.012

[17] Van Kaam, J.B.C.H.M., Finocchiaro, R., Vitale, M., Pinelli, F., Scimonelli, M., Vitale, F., Portolano, B., Oltenacu, P.A. and Caracappa, S., (2008) Prion Protein Gene Frequencies in Three Sicilian Dairy Sheep Populations. Italian Journal of Animal Science, 7, 87-94. http://dx.doi.org/10.4081/ijas.2008.87

[18] Di Patti, C., Di Salvo, R., Di Trapani, F. and Schimmenti, V. (2013) Les restesfauniques du déportoir. In: Lesnes, É. and Poisson, J.M., Eds., Calathamet. Archéologie et histoire d'un château normand en Sicile, École française de Rome, Rome, 283-298.

[19] Sarà, M. (2013) Les restes fauniques du déportoir. In: Lesnes, É. and Poisson, J.M., Eds., Calathamet. Archéologie et histoire d'un château normand en Sicile, École française de Rome, Rome, 299-304.

[20] Cooper, A. and Poinar, H.N. (2000) Ancient DNA: Do It Right or Not at All. Science, 289, 1139. http://dx.doi.org/10.1126/science.289.5482.1139b

[21] Yang, D.Y., Eng, B., Waye, J.S., Dudar, J.C. and Saunders, S.R. (1998) Technical Note: Improved DNA Extraction from Ancient Bones Using Silica-Based Spin Columns. American Journal of Physical Anthropology, 105, 539-543. http://dx.doi.org/10.1002/(SICI)1096-8644(199804)105:4<539::AID-AJPA10>3.0.CO;2-1

[22] Acutis, P.L., Colussi, S., Riina, M.V., Giovannini, T., Trisorio, S., Maniaci, M.G., Zuccon, F. and Peletto, S. (2010) 
Absence of the Alleles $\mathrm{AT}_{137} \mathrm{RQ}$ e $\mathrm{ARQK}_{176}$ Protective to Scrapie in Ovine Piedmontese Breeds. Proceedings of 19th SIPAOC Conference, Rimini, 16, 53.

[23] Hofreiter, M., Jaenicke, V., Serre, D., Haeseler, A.V. and Pääbo, S. (2001) DNA Sequences from Multiple Ampli- fications Reveal Artefacts Induced by Cytosine Deamination in Ancient DNA. Nucleic Acids Research, 29, 4793-4799. http://dx.doi.org/10.1093/nar/29.23.4793

[24] Acín, C., Martìn-Burriel, I., Goldmann, W., Lyahyai, J., Monzòn, M., Bolea, R., Smith, A., Rodellar, C., Badiola, J.J. and Zaragoza, P. (2004) Prion Protein Gene Polymorphisms in Healthy and Scrapie-Affected Spanish Sheep. Journal of General Virology, 85, 2103-2110. http://dx.doi.org/10.1099/vir.0.80047-0

[25] Hunter, N., Goldmann W., Foster J.D., Cairns, D. and Smith, G. (1997) Natural Scrapie and PrP Genotype: CaseControl Studies in British Sheep. Veterinary Record, 141, 137-140. http://dx.doi.org/10.1136/vr.141.6.137

[26] Sipos, W., Kraus, M., Schmool, F., Achmann, R. and Baumgartner, W. (2002) PrP Genotyping of Austrian Sheep Breeds. Journal of Veterinary Medicine Series A, 49, 415-418. http://dx.doi.org/10.1046/j.1439-0442.2002.00472.x

[27] Reale, S., Sìneo, L., Macrì, D., Bivona, M., Arcoleo, L., Risi, M., Cosenza, M. and Vitale, F. (2014) Ancient DNA Polymorphisms Analysis to Investigate Scrapie Susceptibility in Sicilian Sheep Remains from Medieval Archaeological Sites. Proceedings of PRION 2014 Conference, 8, 67. 